\title{
FAKTOR-FAKTOR YANG MEMENGARUHI FINANCIAL SATISFACTION BURUH DI KOTA SURABAYA
}

\author{
Cicik Mahmudah Mukhafi \\ Universitas Negeri Surabaya \\ cicikmukhafi16080574059@mhs.unesa.ac.id
}

\begin{abstract}
The high value of wages is influenced by the high level of living needs as well. A high standard cost of living can cause financial distress for workers. Individuals with high incomes but don't have any skill to control their financial situation can cause financial problems. Consequently, individual financial satisfaction is low. This study conducted to determine the influence between financial attitude and financial literacy toward financial satisfaction with financial management behavior as a mediating variable. The respondents are 121 workforces from companies in the Rungkut Industry area (SIER) as samples. This research using quota sampling and collecting data by online questionnaires. This study uses Structural Equation Model (SEM) and processed by AMOS 2.4. The result shows that only financial management behavior can affect financial satisfaction. Meanwhile, variable financial attitude, financial literacy can not affect on financial satisfaction. Financial attitude and financial literacy also can not affect on financial management behavior. This study indicated that financial management behavior can not mediate between financial attitude on financial satisfaction and financial literacy on financial satisfaction.
\end{abstract}

Keywords: financial attitude; financial literacy; financial management behavior; financial satisfaction.

\section{PENDAHULUAN}

Perekonomian akan mengalami pertumbuhan sejalan dengan peningkatan produksi barang dan jasa setiap tahunnya. Pertumbuhan ekonomi akan memengaruhi pergerakan beberapa sektor salah satunya ialah sektor produksi. Sektor produksi akan memerlukan tenaga kerja sebagai modal utama dalam menggerakkan proses kegiatan produksi. Pada 2018, jumlah angkatan kerja di Indonesia sebesar 133,94 juta orang. Jumlah angkatan kerja mengalami kenaikan sebesar 2,39 juta orang dibandingkan tahun 2017. 133,94 juta orang angkatan kerja tersebut terdiri dari 127,07 juta orang sebagai penduduk bekerja dan 6,87 juta orang sebagai pengangguran (BPS RI, 2018).

Penduduk yang bekerja berdasarkan status pekerjaan utama terdiri dari buruh/karyawan/pegawai, penduduk yang bekerja berusaha sendiri, penduduk yang berusaha dibantu buruh tidak tetap, berusaha dibantu buruh tetap, pekerja keluarga tak dibayar, pekerja bebas di nonpertanian, dan pekerja bebas di pertanian. Buruh/ karyawan/ pegawai berada pada urutan tertinggi yakni sebesar 38,11 persen, status berusaha sendiri sebanyak 18,58 persen, berusaha dibantu buruh tidak tetap sebesar 16,48 persen, sebanyak 14,56 persen menunjukkan pekerja keluarga/tak dibayar, pekerja bebas di non pertanian sebanyak 4,99 persen, berusaha dibantu buruh tetap sebanyak 3,68\%, sementara pekerja bebas di pertanian sebesar 3,60 persen berada di urutan terendah (BPS RI, 2018).

Upah merupakan bentuk imbalan jasa bagi pekerja/buruh yang menjadi hak atas pekerjaan mereka. Upah akan dibatasi berdasarkan UMR (Upah Minimum Regional) yaitu Upah Minimum Kabupaten/ Kota/ Provinsi. Pemerintah menetapkan kenaikan UMP di Indonesia pada tahun 2019 sebesar 8,03 persen. Provinsi dengan tingkat UMP tertinggi yaitu DKI Jakarta sebesar Rp3.940.973. Sementara itu, Jawa Timur adalah salah satu provinsi yang memiliki nilai UMP tertinggi di Pulau Jawa yang berada diurutan ke empat dibandingkan enam provinsi lainnya. UMP DKI Jakarta sebesar Rp3.940.973, Banten dengan UMP sebesar Rp2.267.965, Jawa Barat sebesar Rp1.668.372, Jawa Timur sebesar Rp1.630.059, sedangkan Jawa Tengah sebesar Rp1.605.396 dan tingkat UMP terendah di Pulau Jawa adalah provinsi DIY Yogyakarta sebesar Rp1.570.922 (Deny, 2018).

Himawan Estu Bagijo selaku Kepala Dinas Tenaga Kerja dan Transmigrasi Jawa Timur menyatakan bahwa nilai UMK di Jawa Timur mengalami kenaikan sebesar 8,3 persen yang telah disepakati oleh 
serikat pekerja dan pengusaha. Upah tertinggi di Provinsi Jawa Timur ditetapkan di lima wilayah dengan nilai sebesar Rp3,8 juta. Pada urutan pertama, Kota Surabaya unggul memiliki nilai UMK sebesar Rp3.871.053. Diikuti Kabupaten Gresik sebesar Rp3.867.874, UMK Kabupaten Sidoarjo sebesar Rp3.864.696, UMK Kabupaten Pasuruan Rp3.861.518, dan Kabupaten Mojokerto pada urutan kelima sebesar Rp3.851.983 (Faizal, 2018).

Surabaya merupakan Ibu Kota Provinsi Jawa Timur. Sebesar 64,07 persen dari penduduk usia kerja merupakan pekerja yang berstatus sebagai buruh/karyawan/pegawai. Kota Surabaya memiliki nilai UMK yang cukup tinggi yang dipengaruhi oleh tingkat Kebutuhan Hidup Layak yang tinggi pula. Kebutuhan Hidup Layak merupakan ketentuan kebutuhan hidup yang menjadi standar biaya yang harus dipenuhi pekerja agar dapat menjalani kehidupan yang baik dari segi fisik, non fisik, dan sosial. Badan Pusat Statistik (BPS) dan Asosiasi Pengusaha Indonesia (Apindo) menyatakan bahwa Surabaya sebagai salah satu kota metropolis di Indonesia memiliki angka KHL sebesar Rp 2,38 juta dan upah minimum sebesar Rp 3,29 juta pada tahun 2017 (economy.okezone.com, 2017).

Taraf kebutuhan hidup yang cukup tinggi dapat menimbulkan kesulitan keuangan bagi para pekerja. Dengan nilai UMK di Surabaya yang cukup tinggi, maka diharapkan tingkat kepuasan keuangan pekerja juga tinggi. Namun, individu yang memiliki pendapatan tinggi, jika tidak mampu mengelola keuangannya secara baik akan menghadapi beberapa masalah situasi keuangan seperti tidak dapat membayar tagihan tepat waktu, tidak mampu membayar pinjaman, tidak memiliki perencanaan pensiun, dan tidak memiliki tabungan. Akibatnya, kepuasan keuangan individu rendah (Arifin, 2018).

Individu dikatakan mencapai tujuan keuangan apabila telah mencapai kepuasan keuangan (financial satisfaction). Financial satisfaction sering diartikan terkait banyaknya uang yang dimiliki oleh seseorang. Namun, faktanya financial satisfaction mengukur tingkat kepuasan seseorang terhadap kondisi keuangan yang dimiliki berdasarkan pemahaman mereka terkait kebutuhan keuangan pribadinya. Dapat dikatakan bahwa setiap individu dapat memiliki kondisi keuangan yang sama, tetapi tidak menutup kemungkinan mereka akan mengalami tingkat kepuasan keuangan yang berbeda (Andani, 2018).

Menurut Falahati et al. (2012), financial attitude dan financial literacy menjadi faktor yang mampu memengaruhi financial satisfaction. Darmawan dan Pamungkas (2019) menyatakan bahwa seseorang dengan financial attitude yang tinggi maka tingkat kepuasan keuangan seseorang akan tinggi pula. Sedangkan, penelitian Yap et al. (2018) menunjukkan hasil bahwa financial satisfaction tidak dipengaruhi oleh financial attitude.

Falahati et al. (2012) menambahkan faktor lain sebagai pengaruh financial satisfaction ialah financial literacy. Financial literacy adalah sebuah pengetahuan yang menjadi dasar seseorang untuk berpikir cerdas dalam menggunakan uang (Hasibuan, Lubis, \& HR, 2018). Financial literacy berkaitan dengan penggunaan konsep dan prosedur yang tepat dalam proses pengambilan keputusan dibidang keuangan (Santoso, 2017). Hal tersebut tidak sejalan dengan penelitian Yap et al. (2016) yang menjelaskan bahwa financial literacy tidak memengaruhi financial satisfaction.

Darmawan dan Pamungkas (2019) menyatakan bahwa financial satisfaction dapat dipengaruhi oleh variabel financial management behavior. Berdasarkan penelitian Andani (2018), variabel financial behavior memberikan pengaruh positif pada financial satisfaction. Perilaku seseorang yang baik dalam memperlakukan, mengelola, dan menggunakan uang akan meningkatkan rasa kepuasan seseorang terhadap finansialnya.

Ameliawati \& Setiyani (2018) menjelaskan hasil sikap finansial merupakan kontributor penunjang keberhasilan maupun kegagalan faktor finansial. Sikap yang baik dapat memunculkan perilaku yang baik. Sikap keuangan yang baik dapat diterapkan dalam mewujudkan perilaku keuangan yang baik dan tepat. Berbeda dengan penelitian Rizkiawati \& Asandimitra (2018) yang menunjukkan hasil bahwa financial attitude tidak mampu memengaruhi financial management behavior. 
Cicik Mahmudah Mukhafi. Faktor-faktor yang Memengaruhi Financial Satisfaction Buruh di Kota Surabaya

Financial literacy diartikan sebagai acuan terkait kemampuan dalam mengelola keuangan yang mampu menunjang pencapaian hidup menjadi lebih sejahtera. Individu yang memiliki sikap finansial yang baik, akan memiliki financial literacy yang baik pula. Financial literacy yang baik menjadikan individu mampu menentukan keputusan yang baik dan tepat untuk kehidupan masa depan mereka terutama dalam pengelolaan keuangannya (Ameliawati \& Setiyani, 2018). Sementara itu, hasil penelitian Yap et al. (2016) dan Sugiyanto (2019) menjelaskan financial literacy tidak mampu memengaruhi financial management behavior. Yap et al. (2018) menyatakan bahwa financial behavior adalah variabel mediasi karena variabel ini ditentukan oleh financial attitude dan financial literacy yang memiliki pengaruh dalam menentukan kepuasan.

Penelitian ini bertujuan untuk menganalisis pengaruh financial attitude, financial literacy dan financial management behavior terhadap financial satisfaction pada buruh di Kota Surabaya. Selain itu, penelitian ini bertujuan untuk mengetahui pengaruh financial management behavior sebagai variabel mediasi antara financial attitude dan financial literacy terhadap financial satisfaction pada buruh di Kota Surabaya.

\section{KAJIAN PUSTAKA DAN PENGEMBANGAN HIPOTESIS}

\section{Theory of Planned Behavior (TPB)}

Theory of Planned Behavior (TPB) yang dikemukaan oleh Ajzen (1991) menjelaskan bagaimana seseorang berperilaku yang didasari atas adanya maksud dan tujuan yang ingin dicapai. Ajzen (2005) menambahkan faktor yang melatarbelakangi individu dalam menduga perilaku seseorang karena dipengaruhi beberapa hal antara lain personal, informasi, dan sosial. Teori ini menjadi dasar untuk menjelaskan variabel bebas dalam penelitian ini meliputi financial attitude, financial literacy, dan financial management behavior.

\section{Subjective Well Being (SWB)}

Diener et al. (2000) mengasumsikan unsur penting dari kehidupan yang baik adalah orang tersebut menyukai hidupnya sendiri. Teori Subjective Well Being (SWB) merupakan evaluasi pengetahuan dan sikap seseorang dari kehidupannya. Subjective Well-Being menjelaskan kombinasi nilai positif serta kepuasan hidup individu, dimana setiap individu memiliki kepuasan hidup yang berbeda-beda (Santoso, 2017). Dalam penelitian ini, subjective well-being theory digunakan untuk menjelaskan variabel financial satisfaction.

\section{Financial Satisfaction}

Kepuasan keuangan merupakan komponen dasar dari kebahagiaan yang berasal dari usaha yang dilakukan seseorang. Kepuasan keuangan menjadi elemen dari kepuasan hidup. Orang yang puas secara finansial adalah orang yang puas dengan kehidupannya (Ali, Ali, \& Haq, 2019). Beberapa indikator yang dapat mengukur financial satisfaction antara lain yaitu melihat sudut pandang prribadi terhadap pendapatannya, mengelola masalah keuangannya, menemukan kebutuhan dasarnya, memiliki hutang atau tidak, menabung, memastikan ketersediaan uang untuk masa depannya, menentukan tujuan hidupnya (Hasibuan et al., 2017).

\section{Financial Management Behavior}

Financial management behavior diartikan sebagai perilaku individu dalam memanajemen keuangannya untuk diterapkan dalam kehidupan sehari-hari (Kholilah \& Iramani, 2013). Perilaku manajemen keuangan berhubungan dengan tanggungjawab dalam mengelola keuangan yang dimiliki oleh seseorang. Baik buruknya perilaku keuangan tidak hanya bergantung pada modal kepercayaan terhadap kemampuan diri sendiri, tetapi juga dengan memperhatikan kemampuan aktual maupun faktor pendukung lainnya (Asandimitra \& Kautsar, 2019). Perilaku manajemen keuangan yang efektif akan mendorong kesejahteraan keuangan yang positif bagi seseorang. Sedangkan, kegagalan dalam mengelola keuangan akan mengakibatkan dampak jangka panjang dan dampak sosial yang negatif (Thi, Mien, \& Thao, 2015). Financial management behavior dapat diukur dengan beberapa hal yaitu mengetahui besarnya pengeluaran, pembayaran tagihan, perencanaan keuangan yang dimiliki, ketersediaan uang untuk diri sendiri dan keluarga, tabungan (Kholilah \& Iramani, 2013). 


\section{Financial Attitude}

Financial attitude dapat didefinisikan sebagai kehendak individu menghadapi masalah keuangan (Rai, Dua, \& Yadav, 2019). Financial attitude berhubungan dengan sebuah pola pikir, opini, serta evaluasi oleh individu terkait hal keuangan yang diwujudkan melalui sikap (Asandimitra \& Kautsar, 2019). Menurut Mien \& Thao (2015), financial attitude adalah sebuah sikap yang dapat membentuk cara individu dalam melakukan manajemen keuangan seperti berinvestasi, menabung, dan membelanjakan uang. Menurut Furnham (1984), ada enam indikator pengukuran financial attitude antara lain obsesi, kekuatan, usaha, ketidakcukupan, penyimpanan, keamanan (Herdjiono \& Damanik, 2016).

\section{Financial Literacy}

Financial literacy menjadi acuan untuk mengukur pemahaman individu dalam menggunakan informasi yang berkaitan dengan keuangan pribadi yang mereka miliki (Huston, 2010). Individu yang memahami konsep keuangan dengan baik berdampak pada pengambilan keputusan yang baik dan meningkatkan perilaku keuangan. Financial literacy mendasari seseorang dalam mengambil suatu keputusan dibidang keuangan. Seseorang dapat memiliki financial literacy dengan cara meningkatkan kemampuan keuangan dan menggunakan beberapa alat keuangan (Kautsar \& Asandimitra, 2019). Chen \& Volpe (1998) mengemukakan 4 indikator literasi keuangan antara lain manajemen keuangan pribadi (personal finance), simpanan (saving) dan pinjaman (borrowing), asuransi (insurance), dan investasi (investment).

\section{Hubungan antar Variabel}

Financial attitude dijelaskan oleh theory of planned behavior yang berkaitan dengan aspek personal yaitu sikap (Rizkiawati \& Asandimitra, 2018). Sikap keuangan seseorang ditunjukkan dengan pola pikir yang baik terhadap keuangan. Jika seseorang memikirkan keuangan dengan baik, akan berpengaruh terhadap kualitas keuangan serta kepuasan keuangan (Santoso, 2017). Menurut Arifin (2018), terdapat pengaruh positif antara financial attitude terhadap financial satisfaction. Hal tersebut ditunjukkan oleh kemampuan untuk mendapatkan pemasukan dan pengeluaran, kemampuan untuk menyimpan uang (menabung), menetapkan tujuan finansial, dan kemampuan memenuhi tujuan keuangan di masa mendatang. Jika seseorang memiliki sikap dalam mengelola keuangan dengan baik, akan mendorong tercapainya kemakmuran kepuasan keuangan (Halim \& Astuti, 2015). Hal tersebut didukung oleh penelitian Darmawan \& Pamungkas (2019) yang menyatakan bahwa individu dengan financial attitude yang baik akan mendorong tercapainya financial satisfaction dengan baik.

\section{H1: Financial attitude mampu memengaruhi financial satisfaction.}

Theory of Planned Behavior (TPB) oleh Ajzen (2005) menjelaskan seseorang dalam menduga psikologis manusia melalui faktor informasi. Financial literacy menunjukkan informasi yang diperoleh seseorang berupa pengetahuan tentang keuangan. Financial literacy berguna untuk kehidupan seseorang dalam membuat keputusan keuangan (Chen \& Volpe, 1998). Keputusan keuangan akan meningkatkan kesejahteraan dalam financial satisfaction. Literasi keuangan akan membantu individu dalam mencapai kesejahteraan keuangan. Kebutuhan akan terpenuhi karena literasi keuangan diterapkan dalam kehidupan sehari-hari untuk pengambilan keputusan keuangan yang berdampak terhadap kesejahteraan keuangan (Hasibuan et al., 2017). Hasil penelitian oleh Santoso (2017) menunjukkan ada pengaruh antara financial literacy terhadap financial satisfaction.

\section{H2: Financial literacy mampu memengaruhi financial satisfaction.}

Theory of Planned Behavior oleh Ajzen (1991) mendasari bagaimana seseorang berperilaku. Financial management behavior menjadi faktor yang memengaruhi financial satisfaction. Baik buruknya perilaku keuangan seseorang akan memengaruhi tingkat kepuasan keuangan yang dirasakan oleh orang tersebut (Halim \& Astuti, 2015). Coşkuner (2016) menjelaskan bahwa financial management behavior memberikan pengaruh terhadap financial satisfaction. Seseorang yang menerapkan perilaku keuangan dengan baik dapat meningkatkan kepuasan keuangan yang mereka miliki. Perilaku keuangan yang baik dapat mendorong tercapainya tujuan keuangan sehingga akan mewujudkan kepuasan keuangan pada 
Cicik Mahmudah Mukhafi. Faktor-faktor yang Memengaruhi Financial Satisfaction Buruh di Kota Surabaya

diri seseorang (Yap et al., 2018). Penelitian oleh Arifin (2018) menyebutkan bahwa financial management behavior memberikan pengaruh terhadap financial satisfaction.

\section{H3: Financial management behavior mampu memengaruhi financial satisfaction.}

Financial attitude berkaitan dengan aspek personal yaitu sikap yang didasari pada theory of planned behavior. Sikap keuangan dicirikan dapat menggolongkan kebutuhan yang diperlukan dan lebih cerdas dalam menggunakan uang (Rizkiawati \& Asandimitra, 2018). Penelitian Armilia \& Isbanah (2019) menunjukkan hasil financial attitude terbukti mampu memengaruhi financial behavior. Dapat diartikan jika individu yang memiliki sikap keuangan baik akan mewujudkan perilaku keuangan yang dimiliki menjadi lebih baik. Hasil penelitian Herdjiono \& Damanik (2016), financial attitude berpengaruh positif terhadap variabel financial management behavior. Sejalan dengan penelitian Pusparini \& Krisnawati (2019); Listiani (2017).

\section{H4: Financial attitude mampu memengaruhi financial management behavior.}

Variabel financial literacy berkaitan dengan aspek informasi pada theory of planned behavior yang dikemukakan oleh Ajzen (2005). Informasi yang diperoleh akan memengaruhi pengambilan keputusan sehingga pengelolaan keuangan akan tertata dengan baik dan mengurangi adanya masalah keuangan (Pusparini \& Krisnawati, 2019). Financial literacy mampu memengaruhi financial management behavior. Tingginya tingkat financial literacy akan memengaruhi perilaku manajemen keuangan yang dimiliki individu menjadi lebih baik (Ameliawati \& Setiyani, 2018). Financial literacy yang tinggi pada seseorang dapat mendorong financial management behavior menjadi lebih baik yang akan meningkatkan kecerdasan seseorang untuk mengatur keuangannya dengan baik (Asandimitra \& Kautsar, 2019). Hasil penelitian Laily (2016) yang menunjukkan bahwa tingkat pengetahuan keuangan yang tinggi mempengaruhi kemampuan individu dalam mengelola keuangan yang mereka miliki.

\section{H5: Financial literacy mampu memengaruhi financial management behavior.}

Penelitian ini didukung oleh teori Subjective Well-Being (SWB) oleh Diener et al. (2000) yang menjelaskan bahwa kepuasan individu dapat diukur secara subjektif oleh individu tersebut. Faktor yang menjadi acuan ialah sikap serta perilaku yang dimiliki individu. Sikap maupun perilaku dijelaskan oleh Theory of Planned Behavior (Rizkiawati \& Asandimitra, 2018). Menurut Armilia \& Isbanah (2019), seseorang yang memiliki financial satisfaction akan terbentuk dari financial attitude melalui financial behavior terlebih dahulu. Perilaku keuangan sebagai variabel mediasi dari hubungan antara sikap keuangan dengan kepuasan keuangan menunjukkan hasil yang positif. Arifin (2018) menyatakan bahwa financial management behavior dapat memediasi pengaruh antara financial attitude dengan financial satisfaction.

H6: Financial management behavior memediasi financial attitude terhadap financial satisfaction.

Penelitian ini didasari dengan teori Subjective Well-Being (SWB) oleh Diener et al. (2000) yang menyatakan bahwa kepuasan seseorang diukur secara subjektif oleh individu tersebut. Peran Theory of Planned Behavior untuk menjelaskan variabel financial literacy. Seseorang dengan literasi keuangan yang tinggi akan memahami dan mampu mengelola keuangan dengan baik dalam kehidupan sehari-hari sehingga akan berdampak baik pada kondisi keuangannya (Hasibuan et al. 2018). Falahati et al. (2012) menyatakan bahwa financial literacy mampu memengaruhi financial satisfaction dengan mengetahui pengaruh mediasi variabel financial management behavior pada hubungan ini. Hasil penelitian Yap et al. (2018) menjelaskan financial management behavior adalah variabel mediasi karena variabel tersebut ditentukan oleh financial literacy.

H7: Financial management behavior memediasi financial literacy terhadap financial satisfaction. 


\section{METODE PENELITIAN}

Penelitian ini tergolong penelitian kausalitas. Metode yang digunakan ialah metode kuantitatif. Sumber data menggunakan data primer dengan menyebarkan kuesioner penelitian secara online. Variabel independen meliputi financial attitude dan financial literacy. Variabel dependen yang digunakan yaitu financial satisfaction. Terdapat variabel mediasi dalam penelitian ini yakni financial management behavior. Populasi penelitian mencakup masyarakat yang memiliki status pekerjaan sebagai buruh/ karyawan/ pegawai di Kota Surabaya. Jumlah sampel penelitian didapat dari 5 dikali jumlah indikator sebanyak 22 . Kemudian ditambah dengan $10 \%$ yangenghasilkan sebanyak 121 responden $(5$ x $22=110$ $+10 \%=121$ ). Responden merupakan pekerja dari beberapa perusahaan di kawasan Rungkut Industri Surabaya (SIER) yang diambil menggunakan teknik quota sampling. Pemilihan beberapa perusahaan untuk dijadikan sampel tidak menggunakan prosedur secara detail hanya mengandalkan judgment pribadi peneliti. Sampling kuota dapat dikatakan sebagai sampling judgmental yang dilakukan dengan menetapkan kategori kuota kemudian memilih sampel secara bebas agar kuota terpenuhi dengan syarat elemen yang dipilih sesuai dengan karakteristik yang telah ditentukan. Karakteristik responden dalam penelitian ini adalah pekerja yang memiliki gaji tetap per bulan dan pekerja yang berdomisili Surabaya. Penelitian ini menggunakan Structural Equation Modeling (SEM) sebagai teknik analisis data dengan bantuan alat analisis program AMOS versi 24.

\section{HASIL DAN PEMBAHASAN}

\section{Uji Validitas dan Uji Reliabilitas}

Uji validitas yang dilakukan pada skala Gutman variabel financial literacy menggunakan perhitungan Koefisien Reprodusibilitas yang menghasilkan nilai $0,904 \geq 0,90$ dan Koefisien Skalabilitas menunjukkan hasil $0,808 \geq 0,60$. Nilai koefisien tersebut melebihi kriteria yang telah ditentukan dan variabel financial literacy dapat dikatakan valid. Sedangkan uji reliabilitas menggunakan metode KR20 yang menghasilkan nilai koefisien sebesar 0,416 yang berada pada tingkat sedang dan dapat dikatakan reliabel.

Uji validitas dan reliabilitas skala Likert pada financial attitude, financial literacy, financial management behavior serta financial satisfaction di uji dengan bantuan program AMOS. Berdasarkan hasil perhitungan, besarnya nilai AVE pada masing-masing variabel telah memenuhi ketentuan yaitu diatas $\geq 0,50$. Financial attitude menghasilkan AVE sebesar 0,627, financial literacy sebesar 0,522, financial management behavior memperoleh nilai AVE sebesar 0,511, dan variabel financial satisfaction sebesar 0,525 dengan nilai discriminant validity pada masing-masing variabel berada diatas nilai AVE. Uji reliabilitas diperolah hasil $\mathrm{CR}$ telah melebihi kriteria $\geq 0,70$ pada masing-masing variabel. Hasil perhitungan CR financial attitude yaitu 0,891, financial literacy 0,762, financial management behavior 0,837 , dan financial satisfaction menghasilkan nilai CR 0,885.

\section{Uji Outlier}

Uji Outlier dapat dilihat pada mahalonobis distance dengan ketentuan nilai $\mathrm{P} 2 \geq 0,05$. Terdapat beberapa responden yang memiliki nilai $\mathrm{P} 2 \leq 0,05$ yaitu pada responden nomor $17,3,27,12,102,36$, 68, dan 4. Data tersebut perlu dihapus karena tidak lolos uji outlier dan tersisa 113 dari 121 responden.

\section{Uji Normalitas}

Uji normalitas dilihat pada output AMOS assessment of normality dengan ketentuan nilai C.R berada pada $-2,58 \leq 2,58$. Apabila tidak memenuhi asumsi tersebut maka perlu dieliminasi dan tidak diikutkan pada tahapan analisis selanjutnya. Terdapat beberapa data yang memiliki sebaran tidak normal yaitu indikator Y.2, Z.2, X2.3, dan X2.2 yang keluar dari batas ring, sehingga perlu dieliminasi agar lolos uji normalitas.

\section{Uji Kelayakan Model}

Model penelitian dikatakan layak dan dapat diterima karena terdapat tiga kriteria yang nilainya memenuhi dari lima kriteria yang digunakan. Nilai GFI sebesar 0.909 tergolong baik karena $\geq 0.900$. 
Cicik Mahmudah Mukhafi. Faktor-faktor yang Memengaruhi Financial Satisfaction Buruh di Kota Surabaya

Nilai AGFI 0.853 dan NFI 0.841 masih berada pada nilai minimum yang seharusnya $\geq 0.900$ sehingga dikatakan marjinal. Nilai TLI $0.954 \geq 0.950$ telah memenuhi kriteria dan tergolong baik. Sedangkan nilai RMSEA berada di antara $0.080 \leq X \geq 0.050$ yaitu sebesar 0.052 yang masih tergolong baik. Hasil ini juga dapat dilihat di Tabel 1 dan Gambar 1.

Tabel 1.

\section{UJI KELAYAKAN MODEL}

\begin{tabular}{lccc}
\hline Goodness of Fit & Kriteria & Nilai & Keterangan \\
\hline GFI & $\geq 0,900$ & 0,909 & Baik \\
AGFI & $\geq 0,900$ & 0,853 & Marjinal \\
TLI & $\geq 0,950$ & 0,954 & Baik \\
NFI & $\geq 0,900$ & 0,841 & Marjinal \\
RMSEA & $0,080 \leq X \geq 0,050$ & 0,052 & Baik \\
\hline
\end{tabular}

Sumber: Outpus AMOS

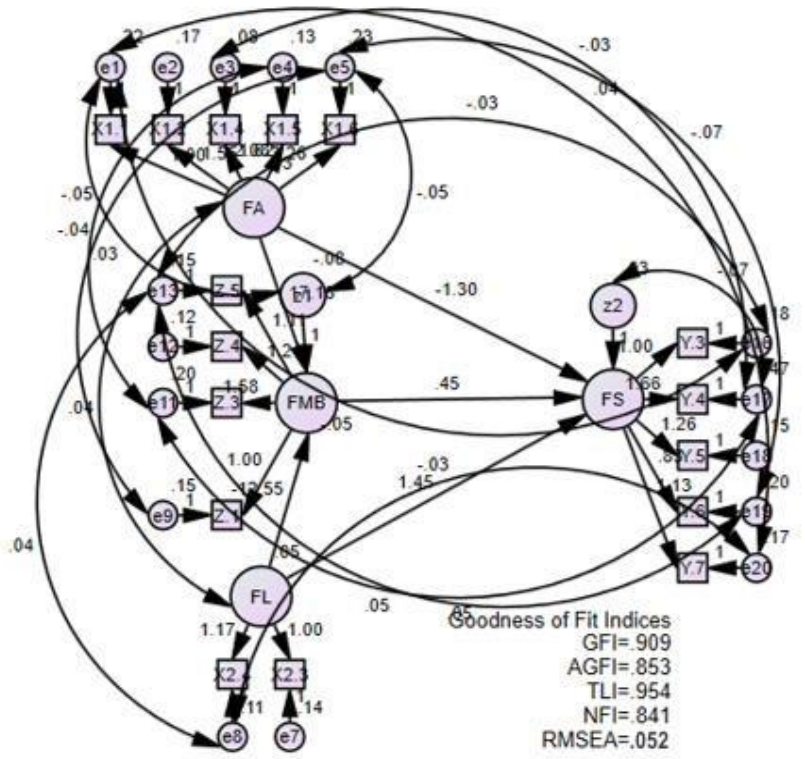

Sumber: Output AMOS

Gambar 1. MODEL AKHIR SEM

\section{Uji Hipotesis}

Tabel 2.

UJI HIPOTESIS

\begin{tabular}{|c|c|c|c|c|c|c|c|}
\hline \multicolumn{4}{|c|}{ Hipotesis } & Estimate & S.E. & C.R. & $\mathbf{P}$ \\
\hline $\mathrm{H} 1$ & FS & $\leftarrow$ & FA & -1.297 & 1.972 & -.658 & .511 \\
\hline $\mathrm{H} 2$ & FS & $\leftarrow$ & FL & 1.451 & 1.451 & 1.000 & .317 \\
\hline $\mathrm{H} 3$ & FS & $\leftarrow$ & FMB & .452 & .214 & 2.114 & .035 \\
\hline $\mathrm{H} 4$ & FMB & $\leftarrow$ & FA & 17.178 & 62.750 & .274 & .784 \\
\hline H5 & FMB & $\leftarrow$ & FL & -12.552 & 48.628 & -.258 & .796 \\
\hline
\end{tabular}

Sumber: Output AMOS

Uji hipotesis menunjukkan bahwa hipotesis diterima apabila memenuhi nilai signifikansi yaitu $\leq 0,05$. Terdapat satu hipotesis yang diterima yaitu $\mathrm{H} 3$ karena nilai P sebesar $0,035 \leq 0,05$. Beberapa hipotesis yang lain tidak memenuhi kriteria karena memiliki nilai $\geq 0,05$. H1 memiliki nilai $\mathrm{P}$ sebesar $0.511, \mathrm{H} 2$ sebesar 0.317, H4 sebesar 0.784, dan H5 memiliki nilai P sebesar 0796. Hasil ini juga dapat dilihat Gambar 1 dan Tabel 2. 
Untuk mengetahui peran mediasi atau hubungan tidak langsung dalam penelitian ini dilakukan dengan menghitung rumus Sobel Test. Hasil perhitungan hubungan tidak langsung variabel financial management behavior antara financial attitude terhadap financial satisfaction menunjukkan hasil sebesar 0,246. Sedangkan hasil perhitungan hubungan tidak langsung financial management behavior terhadap financial literacy terhadap financial satisfaction menunjukkan nilai sebesar -0,231. Nilai signifikansi dari kedua hubungan tidak langsung berada diatas 0,05 sehingga financial management behavior tidak mampu memediasi pengaruh financial attitude terhadap financial satisfaction maupun financial literacy terhadap financial satisfaction.

\section{Pengaruh Financial Attitude terhadap Financial Satisfaction}

Penelitian menunjukkan bahwa tidak ada pengaruh financial attitude terhadap financial satisfaction. Hasil ini sejalan dengan penelitian Yap et al. (2016) yang menjelaskan variabel financial attitude tidak memberikan pengaruh pada financial satisfaction.

Hasil dari penelitian tidak sesuai dengan Theory of Planned Behavior. Sikap yang baik diwujudkan dengan cara berpikir yang baik pula. Semakin baik pola pikir seseorang terhadap keuangannya maka semakin baik kualitas keuangan yang dimiliki. Responden memiliki sikap yang cukup baik terhadap keuangannya. Namun terkadang responden tidak berpikir secara rasional bahwa uang merupakan sesuatu yang bernilai dan harus dipertanggungjawabkan sehingga menyebabkan kualitas keuangan seseorang menjadi tidak sehat. Responden yang tidak berpikir rasional dipengaruhi oleh faktor kebutuhan yang menjadikan responden memiliki sikap konsumtif dengan berbelanja lebih banyak dibandingkan seharusnya karena untuk memenuhi kebutuhan mereka di bulan puasa terutama menuju lebaran. Dapat dikatakan bahwa pandangan responden cukup rendah dalam menyikapi keuangan akibatnya orientasi terhadap kepuasan keuangan belum tercapai.

\section{Pengaruh Financial Literacy terhadap Financial Satisfaction}

Hasil uji hipotesis menunjukkan bahwa tidak terdapat pengaruh financial literacy terhadap financial satisfaction. Penelitian Yap et al. (2016) menjadi pendukung dalam penelitian ini yang menunjukkan hasil financial literacy tidak memengaruhi financial satisfaction.

Hasil dari penelitian tidak sejalan dengan Theory of Planned Behavior yang mendasari financial literacy melalui faktor informasi. Informasi akan melandasi seseorang dalam mengambil keputusan. Namun, setiap responden memiliki tingkat pemahaman yang berbeda-beda, sehingga akan memunculkan adanya keputusan yang berbeda pula pada setiap responden. Baik buruknya tingkat financial literacy yang dimiliki oleh responden tidak akan memengaruhi financial satisfaction, karena financial satisfaction mengukur tingkat kepuasan seseorang terhadap kondisi dan situasi keuangan seseorang.

Tingkat kepuasan tersebut akan berbeda-beda antar responden. Hal ini dapat disebabkan adanya perbedaan karakteristik dan latar belakang responden yang seharusnya ikut dipertimbangkan seperti perbedaan jenis kelamin, usia, jenjang pendidikan yang telah ditempuh, besarnya gaji yang diperoleh sehingga pada hasilnya tidak memberikan gambaran yang sebenarnya. Dalam hal ini, perlu adanya tindakan dari perusahaan tempat responden bekerja dengan cara memberikan bimbingan atau pelatihan untuk meningkatkan melek finansial kepada para pekerja yang diharapkan dapat menumbuhkan kesejahteraan keuangan ke arah yang lebih baik dan mencapai kepuasan keuangan.

\section{Pengaruh Financial Management Behavior terhadap Financial Satisfaction}

Hasil uji hipotesis pengaruh antara financial management behavior terhadap financial satisfaction menunjukkan nilai positif. Artinya semakin baik perilaku individu dalam mengendalikan, mengelola, serta menggunakan keuangannya tentu akan memunculkan hasil keputusan keuangan yang baik. Hal tersebut mengakibatkan individu akan merasa puas terhadap kondisi keuangan yang dimiliki.

Penelitian ini sesuai dengan Theory of Planned Behavior yang mendasari seseorang dalam bertindak. Berdasarkan jawaban kuesioner, responden memiliki tanggungjawab dan perilaku yang baik terutama dalam pengelolaan keuangan. Responden mencerminkan perilaku disiplin yang dapat memengaruhi 
Cicik Mahmudah Mukhafi. Faktor-faktor yang Memengaruhi Financial Satisfaction Buruh di Kota Surabaya

kesejahteraan finansial bagi responden karena responden lebih memilih untuk menghindari adanya tunggakan yang menimbulkan masalah keuangan di kemudian hari. Hal ini dapat memunculkan kepuasan keuangan bagi responden. Hasil penelitian sejalan dengan penelitian Arifin (2018); Armilia \& Isbanah (2019); Andani (2018); Coskuner (2016); Darmawan \& Pamungkas (2019).

\section{Pengaruh Financial Attitude terhadap Financial Management Behavior}

Financial attitude tidak memengaruhi financial management behavior. Sikap keuangan tidak mampu menentukan perilaku keuangan seseorang. Hal ini dikarenakan responden memiliki jawaban yang berbeda-beda diikuti dengan orientasi yang berbeda pula terhadap keuangan yang mereka miliki terutama dalam menyikapi kondisi keuangan yang ada.

Hasil penelitian ini berbeda dengan Theory of Planned Behavior (TPB) yang menyatakan bahwa seseorang dengan sikap keuangan yang baik mampu mendorong perilaku keuangan yang baik. Dalam penelitian ini, beberapa responden jarang membuat perencanaan keuangan dan menabung hanya ketika mendapat sisa dari gaji yang telah dibelanjakan. Jika tidak terdapat sisa dari gaji, maka responden tidak menyimpan uangnya untuk ditabung. Hal ini dapat mengakibatkan kondisi keuangan yang kurang sehat. Responden perlu untuk meningkatkan sikap keuangan dengan mengasah pola berpikir agar menjadi lebih baik terutama terkait hal keuangan sehingga dapat mendorong perilaku keuangan mereka menjadi lebih baik. Penelitian ini didukung oleh hasil penelitian Rizkiawati \& Asandimitra (2018) dan Lianto \& Elizabeth (2017).

\section{Pengaruh Financial Literacy terhadap Financial Management Behavior}

Hasil uji hipotesis menunjukkan bahwa financial literacy tidak berpengaruh terhadap financial management behavior. Hasil tersebut sejalan dengan penelitian Yap et al (2016) yang menjelaskan bahwa variabel financial attitude tidak memengaruhi financial satisfaction.

Implikasi penelitian tidak sesuai dengan Theory of Planned Behavior. Informasi yang diterima dengan baik akan mendorong seseorang dalam pengambilan keputusan dengan beberapa pertimbangan dan cara berpikir yang rasional. Dalam penelitian ini, sebagian responden telah menerapkan pengelolaan keuangannya dengan baik. Seperti perilaku menabung secara rutin. Namun, terdapat pula responden yang kurang memahami pentingnya asuransi dan berinvestasi.

Adapun upaya yang dapat diterapkan perusahaan untuk mengajarkan literasi keuangan antara lain dengan menerapkan program dan sistem yang akan mengerjakan pekerja mengenai cara menabung dan mengelola tabungan, berinvestasi, mengelola pendapatan, dan mengendalikan masa depan keuangan para pekerja.

\section{Pengaruh Financial Attitude terhadap Financial Satisfaction dengan Financial Management Behavior sebagai Variabel Mediasi}

Berdasarkan perhitungan Sobel Test antara financial attitude terhadap financial satisfaction yang dimediasi oleh financial management behavior menunjukkan bahwa financial management behavior tidak mampu memediasi sikap keuangan terhadap kepuasan keuangan sehingga mengakibatkan kepuasan keuangan tidak dapat tercapai.

Hasil penelitian tidak sejalan dengan teori Subjective Well Being yang menjelaskan bahwa kepuasan individu diukur secara subjektif oleh individu tersebut sekaligus. Selain itu, implikasi penelitian berbeda dengan Theory of Planned Behavior yang menjelaskan bahwa seseorang yang menerapkan sikap keuangan diwujudkan dengan pola berpikir yang baik pula. Setiap orang memiliki pola pikir yang berbeda-beda, sehingga bentuk tindakan yang diambil akan berbeda-beda pula. Namun, seseorang dengan sikap keuangan yang baik seperti menyimpan uang tidak menjamin bahwa perilaku dalam pengelolaan keuangan akan berjalan dengan baik. Terlebih lagi, apabila seseorang memiliki taraf kepuasan yang sangat tinggi justru dapat menghambat tercapainya kepuasan keuangan karena tidak memiliki kemampuan dalam mengelola keuangan. Hal tersebut dapat mengakibatkan keuangan seseorang berada pada kondisi yang kurang sehat. 


\section{Pengaruh Financial Literacy terhadap Financial Satisfaction dengan Financial Management Behavior sebagai Variabel Mediasi}

Penelitian ini menunjukkan hasil bahwa financial management behavior tidak mampu memediasi hubungan financial literacy terhadap financial satisfaction. Financial literacy yang dimiliki oleh responden tidak memberikan pengaruh terhadap perilaku mereka dalam mengelola keuangan yang mengakibatkan tidak tercapainya suatu kepuasan keuangan. Implikasi penelitian tidak sesuai dengan Theory of Planned Behavior dan teori Subjective Well Being yang menjelaskan bahwa kepuasan individu dapat diukur secara subjektif oleh individu tersebut. Tingkat literasi atau pengetahuan yang dimiliki seseorang tidak mampu menjamin seseorang dalam bertindak maupun berperilaku secara baik terutama dalam mengelola keuangan yang dimiliki. Dapat dikatakan seseorang dengan tingkat financial literacy yang tinggi belum tentu mampu mengurangi rasa waspada dan kekhawatiran dalam mengelola keuangan di masa mendatang, sehingga tidak dapat dipastikan pengelolaan keuangan tersebut akan berhasil.

\section{KESIMPULAN}

Financial attitude tidak memengaruhi financial satisfaction. Pandangan responden yang rendah dalam menyikapi uang menyebabkan kualitas keuangan tidak sehat dan orientasi tidak tercapai. Financial literacy tidak berpengaruh terhadap financial satisfaction. Tidak semua orang yang melek finansial akan menerapkan pengetahuan keuangan dengan baik. Financial management behavior berpengaruh terhadap financial satisfaction. Para pekerja membayar tagihan tepat waktu untuk menghindari tunggakan yang menimbulkan masalah keuangan. Financial attitude tidak memengaruhi financial management behavior. Beberapa responden jarang membuat perencanaan keuangan dan menabung hanya ketika terdapat sisa dari gaji yang diperoleh. Financial literacy tidak berpengaruh terhadap financial management behavior. Responden kurang memahami dan memerhatikan faktor penunjang keuangan di masa depan seperti asuransi dan investasi. Financial management behavior tidak mampu memediasi pengaruh antara financial attitude terhadap financial satisfaction dan financial literacy terhadap financial satisfaction.

Perusahaan sebagai tempat bekerja perlu mewadahi para pekerja dengan memberikan program atau bimbingan untuk meningkatkan kesadaran dan pengetahuan pekerja dibidang keuangan. Perusahaan dapat bekerjasama dengan pihak terkait untuk menginformasikan produk dan konsep keuangan. Selain itu, pekerja dapat meningkatkan pemahaman tentang produk dan konsep keuangan dengan mencari dan menggali informasi melalui beberapa sumber seperti internet, buku, atau sumber lainnya. Penelitian ini memiliki keterbatasan dalam variabel independen sehingga perlu ditambahkan beberapa variabel seperti locus of control, household income, dan financial socialization pada penelitian selanjutnya. Selain itu, penelitian selanjutnya diharapkan mampu memperluas cakupan penelitian seperti melakukan wawancara ataupun menggunakan objek penelitian yang berbeda dengan ukuran sampel lebih besar.

\section{DAFTAR PUSTAKA}

Ajzen, I. (1991). The Theory of Planned Behavior. Organizational Behavior and Human Decision Processes, 50(2), 179-211. https://doi.org/10.1016/0749-5978(91)90020-T

Ajzen 2005. Attitude, Peronality and Behavior. New York: Open Univerity Press.

Ali, W., Ali, S., \& Haq, A. U. (2019). Influence of Life Events on the Financial Satisfaction of Individuals. IBT Journal of Business studies 15, 123-137. http://jms.ilmauniversity.edu.pk/index.php/jbs/article/view/300

Ameliawati, M., \& Setiyani, R. (2018). The Influence of Financial Attitude, Financial Socialization, and Financial Experience to Financial Management Behavior with Financial Literacy as the Mediation Variable. KnE Social Sciences, 3(10), 811. https://doi.org/10.18502/kss.v3i10.3174 
Cicik Mahmudah Mukhafi. Faktor-faktor yang Memengaruhi Financial Satisfaction Buruh di Kota Surabaya

Andani, N. D. (2018). Pengaruh Income, Financial Knowledge, Financial Behavior dan Childhood Consumer Experience terhadap Financial Satisfaction Pada Pegawai PT Perusahaan Listrik Negara (Persero) Wilayah Sumatera Utara. http://repositori.usu.ac.id/handle/123456789/7266

Arifin, A. Z. (2018). Influence Factors toward Financial Satisfaction with Financial Behavior as Intervening Variable on Jakarta Area Workforce. European Research Studies Journal, 21(1), 90-103.

Armilia, N., \& Isbanah, Y. (2020). Faktor yang Mempengaruhi Kepuasan Keuangan Pengguna Financial Technology di Surabaya. Jurnal Informasi Manajemen (JIM), 8(2018), 39-50.

Asandimitraa, N., Kautsar, A. (2019). The Influence of Financial Information, Financial Self Efficacy, and Emotional Intelligence to Financial Management Behavior of Female Lecturer. Humanities \& Social Sciences Reviews, 7(6), 1112-1124. https://doi.org/10.18510/hssr.201li9.76160

BPS RI. (2018). Keadaan Angkatan Kerja di Indonesia. (https://www.bps.go.id/publication/2018/11/30/6d8a8eb26ac657f7bd170fca/keadaanangkatankerja-di-indonesia-agustus-2018.html. Diakses pada 14 Oktober 2019 Pukul 09:59 WIB)

BPS RI (2018). Berita Resmi Statistik Keadaan Ketenagakerjaan Kota Surabaya. (https://surabayakota.bps.go.id/pressrelease/2018/12/26/118/keadaan-ketenagakerjaan-kotasurabaya--agustus-2018-.html. Diakses pada 14 Oktober 2019 Pukul 09:59 WIB)

Chen, H., \& Volpe, R. P. (1998). An Analysis of Personal Financial Literacy Among College Students. Financial Services Review, Volume 7, Issue 2. 107-128. https://doi.org/10.1016/S10570810(99)80006-7

Coşkuner, S. (2016). Understanding Factors Affecting Financial Satisfaction: The Influence of Financial Behavior, Financial Knowledge and Demographics. Imperial Journal of Interdisciplinary Research, 2(5), 2454-1362. http://www.onlinejournal.in

Darmawan, D., \& Pamungkas, A. S. (2019). Pengaruh Financial Attitude, Financial Behavior, dan Financial Knowledge terhadap Financial Satisfaction. Jurnal Manajerial dan Kewirausahaan, Volume 1, No. 2. 172-181.

Deny, Septian. (2018). Cek Besaran UMP 2019 di 25 Provinsi. Liputan6.com (https://m.liputan6.com/bisnis/read/3685917/cek-besaran-ump-2019-di-25-provinsi. Diakses pada 12 Oktober 2019 Pukul 21:40 WIB)

Diener, E., Lucas, R. E., \& Oishi, S. (2000). Subjective Well-Being. In The Science of Happiness and Life Satisfaction (pp. 63-73). https://doi.org/10.1093/oxfordhb/9780195187243.013.0017

Economy.okezone.com. (2017). Inilah Daftar Kebutuhan Hidup Layak di 7 Kota Besar. (http://economy.okezone.com/amp/2017/05/26/320/1700999/inilahdaftar-kebutuhan-hiduplayak-di-7-kota-besar. Diakses pada 16 Oktober 2019 Pukul 13:00 WIB)

Faizal. (2018). UMK Jatim 2019 Ditetapkan Tertinggi Rp 3,8 Juta Terendah Rp 1,7 juta. Kompas.com. (http://amp.kompas.com/surabaya. Diakses pada 13 Oktober 2019 Pukul 20:00 WIB) 
Falahati, L., Sabri, M. F., \& Paim, L. H. J. (2012). Assessment a model of financial satisfaction predictors: Examining the mediate effect of financial behaviour and financial strain. World Applied Sciences Journal, 20(2), 190-197. https://doi.org/10.5829/idosi.wasj.2012.20.02.1832

Ghozali, I. (2017). Model Persamaan Struktural Konsep dan Aplikasi dengan Program AMOS 24 Update Bayesian SEM (VII). Badan Penerbit Undip.

Halim, Y. K. E., \& Astuti, D. (2015). Financial Stressors, Financial Behavior, Risk Tolerance, Financial Solvency, Financial Knowledge, dan Kepuasan Finansial. Jurnal Finesta, 3(1), 19-23. https://doi.org/10.1109/EDOC.2009.26

Hasibuan, B. K., Lubis, Y. M., \& HR, W. A. (2018). Financial Literacy and Financial Behavior as a Measure of Financial Satisfaction. Advances in Economics, Business and Management Reearch (AEBMR), 46, 503-507. https://doi.org/10.2991/ebic-17.2018.79

Herdjiono, I., \& Damanik, L. A. (2016). Pengaruh Financial Attitude, Financial Knowledge, Parental Income terhadap Financial Management Behavior. Journal of Theory and Applied Management, 9(3), 226-241. https://doi.org/10.20473/jmtt.v9i3.3077

Huston, S. J. (2010). Measuring Financial Literacy. Journal of Consumer Affairs, 44(2), 296-316. https://doi.org/10.1111/j.1745-6606.2010.01170.x

Kautsar, A., Asandimitra, N. (2019). Financial Knowledge as Youth Preneur Success Factor. Journal of Social and Development Science, Vol. 10, No. 2, 2019, pp. 26-32

Kholilah, N. Al, \& Iramani, R. (2013). Studi Financial Management Behavior Pada Masyarakat Surabaya. Journal of Business and Banking, 3(1), 69. https://doi.org/10.14414/jbb.v3i1.255

Laily, N. (2016). Pengaruh Literasi Keuangan Terhadap Perilaku Mahasiswa Dalam Mengelola Keuangan. Journal of Accounting and Business Education, 1(4). https://doi.org/10.26675/jabe.v1i4.6042

Lianto, R., Elizabeth, S. M. (2017). Analisis Pengaruh Financial Attitude, Financial Knowledge, Income terhadap Financial Behavior di Kalangan Ibu Rumah Tangga Palembang (Studi Kasus Kecamatan Ilir Timur I). STMIK GI MDP \& MDP Business School. https://eprints.mdp.ac.id/2365

Listiani, K. (2017). Pengaruh Financial Knowledge, Locus of Control dan Financial Attitude terhadap Financial Management Behavior pada Mahasiswa. STIE Perbanas. Perbanas Institutional Repository. https://eprints.perbanas.ac.id/id/eprint/2917

Malhotra. (2017). Riset Pemasaran Pendekatan Terapan In Pemasaran (4th ed). Jakarta: PT Indeks Mien, N. T. N., \& Thao, T. P. (2015). Factors Affecting Personal Financial Management Behaviors: Evidence from Vietnam. Economics, Finance and Social Sciences Journal, 978-1. http://digital.lib.ueh.edu.vn/handle/UEH/56557

Pusparani, A., \& Krisnawati, A. (2019). Analisis Pengaruh Financial Literacy dan Financial Attitude terhadap Financial Behavior pada Siswa Sekolah Menengah Pertama di Kota Bandung. Jurnal Mitra Manajemen (JMM Online), 72-83. 
Cicik Mahmudah Mukhafi. Faktor-faktor yang Memengaruhi Financial Satisfaction Buruh di Kota Surabaya

Rai, K., Dua, S., \& Yadav, M. (2019). Association of Financial Attitude, Financial Behaviour and Financial Knowledge Towards Financial Literacy: A Structural Equation Modeling Approach. FIIB Business Review, 8(1), 51-60. https://doi.org/10.1177/2319714519826651

Rizkiawati, N. L., \& Asandimitra, N. (2018). Pengaruh Demografi, Financial Knowledge, Financial Attitude, Locus of Control dan Financial Self-Efficacy Terhadap Financial Management Behavior Masyarakat Surabaya. Jurnal Ilmu Manajemen (JIM), 6(3), 93-107.

Santoso, S. H. (2017). Analisis Faktor-faktor yang Mempengaruhi Financial Satisfaction pada Masyarakat di Kota Makassar.

Sugiyono. (2012). Metode Penelitian Kombinasi (Mixed Methods). In Sugiyono. Bandung: CV Alfabeta.

Sugiyono. (2013). In Metode Penelitian Kuantitatif Kualitatif dan R\&D. Bandung: CV Alfabeta.

Sugiyanto, T., Radianto, W. E., Efrata, T. C., \& Dewi, L. (2019). Financial Literacy, Financial Attitude, and Financial Behavior of Young Pioneering Business Entrepreneurs. 2019 International Conference on Organizational Innovation (ICOI 2019), 100(Icoi), 353-358. https://doi.org/10.2991/icoi-19.2019.60

Yap, R. J. C., Komalasari, F., \& Hadiansah, I. (2018). The Effect of Financial Literacy and Attitude on Financial Management Behavior and Satisfaction. Bisnis \& Birokrasi Journal, 23(3). https://doi.org/10.20476/jbb.v23i3.9175 